\title{
The role of advection and turbulent mixing in the vertical distribution of phytoplankton
}

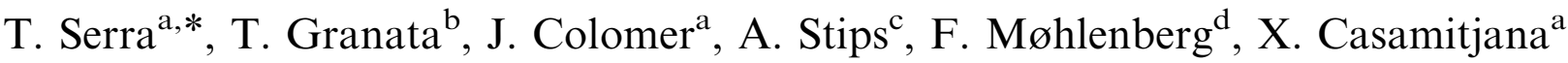 \\ ${ }^{a}$ Department of Physics, University of Girona, Campus Montilivi, E-17071 Girona, Spain \\ ${ }^{\mathrm{b}}$ Ecological Engineering, CEEGS, Ohio State University, 470 Hitchcock Hall, 2070 Neil Avenue, Columbus, OH 43210-1275, USA \\ ${ }^{\mathrm{c}} J R C-S A I / M E$ Unit, Via E. Fermi- T.P. 690, I-21020 Ispra, Italy \\ ${ }^{\mathrm{d}}$ DK1, Agern Alle 11, DK-2970 Hoersholm, Denmark
}

Received 28 June 2001; received in revised form 12 December 2001; accepted 12 December 2001

\begin{abstract}
The purpose of this study is to analyse the role of the flow field on the horizontal and vertical distributions of different phytoplankton populations thriving in the water column of a shallow coastal ecosystem. Two extreme flow conditions are illustrated. The first was a low energetic flow, under calm meteorological conditions and a stratified temperature of the water column. The second flow, coincident with the passage of a storm front, was more energetic resulting in increased mixing that homogenized the temperature in the whole water column. Although the mixing level homogenized the temperature of the water column in the high-energy period, it was not enough to homogenize the temperature in the low-energy period. In contrast, in both periods, the mixing level was enough to homogenize the vertical distribution of particles. A decrease in the concentration of particles from the calm period to the high-energy period was attributed to an advection event with warmer water of lower plankton concentration that resulted in a decrease of the total concentration of suspended particles in the water column. Data are used to test a model of plankton mixing proposed by Ruiz et al. (J. Plankton Res., 18 (1996) 1727).
\end{abstract}

(c) 2003 Elsevier Science B.V. All rights reserved.

Keywords: Advection; Microstructure; Mixing; Eddy diffusivity; Potential density; Particle concentration; Mean current

\section{Introduction}

It is known that different phytoplankton groups occupy different niches in the water column depending on their sizes (Tremblay, Legendre, \& Therriault, 1997). Small phytoplankton cells $(<5 \mu \mathrm{m})$ tend to be ubiquitous in the water column, whereas large phytoplankton cells thrive in a narrow range depending on the hydrodynamic conditions. Even though it is not resolved, this difference in the phytoplankton behaviour has been attributed to several factors, such as the sinking rate of phytoplankton, their photosynthetic efficiency, the uptake of nutrients, advection and grazing, coagulation, among others. Large cells are susceptible to sinking or grazing by small herbivores that do not influence small cells. The export of larger phytoplankton from the surface to the

\footnotetext{
* Corresponding author.

E-mail address: teresa.serra@udg.es (T. Serra).
}

bottom is crucial in order to explain the transport of carbon through the water column.

It is generally well accepted that there is a strong relationship between the vertical mixing of the water column and the distribution of particles within it. Usually, high levels of mixing in the water column are associated with homogeneous distribution of particles. Even though Ryther and Hulburt (1960) and Ignatiaded (1979) showed that particle stratification can occur even when fluid properties appear well mixed, both studies had low vertical resolution of physical and biological data. Other studies, based on vertical microstructure measurements of the fluorescence (Cowles \& Desiderio, 1993; Cowles, Moum, Desiderio, \& Neuer, 1993; Ruiz, 1996; Ruiz, García, \& Rodríguez, 1996), suggested the presence of microstructures in the mixed layer, which might be caused by a photo-adaptative response to the light gradient or also by the energy dissipation level over the water column. 
Mixing has also been found to dominate the coagulation process of particles in a water body (Serra, Colomer, \& Casamitjana, 1997; Serra \& Logan, 1999). In this case, small particles with low settling velocities have been found to coagulate; attaining higher sinking rates than they had previously attained (Li \& Logan, 1997). Other processes like advection can also determine the fate of suspended particles in the water column, as has been demonstrated in previous studies on phytoplankton (Kiørboe et al., 1998) and on suspended sediment particles (Colomer, Serra, Piera, Roget, \& Casamitjana, 2001). Several models (Ruiz et al., 1996; Ruiz, 1996) have been proposed with the aim to evaluate the mixing effect on the vertical distribution of phytoplankton. In these models, advection processes have not been considered.

Despite these studies, the role of mixing in regulating the concentration of particles of different sizes i.e. to the concentration of different populations of microorganisms, has not been adequately demonstrated for field data. In this study, the effects of the mixing and advection processes on the particle concentration of different species in the water column of a shallow coastal system will be compared by combining high-resolution data on current shear, particle size distributions and pigments. Two different energetic conditions are illustrated. A low-energy period, which represents stratified temperatures, and a high-energy period, which represents vertically homogeneous temperatures. In this study, and based on the field data obtained, we also tested the model of plankton mixing proposed by Ruiz et al. (1996) and Ruiz (1996). In this study, we stressed the importance of horizontal transport in regulating plankton distributions in shallow coastal ecosystems.

\section{Theory}

Settling velocity of particles is described by the Stokes equation, provided laminar flow occurs, i.e. inertia forces do not overwhelm viscous forces. The ratio of these two forces is balanced by the Reynolds number, $R e=w d / v$ where $d$ is the particle diameter, $w$ is its settling velocity and $v$ is the fluid kinematic viscosity. For $R e<0.1$, there is very little departure from Stokes equation. The maximum speed velocity reported for algae has been found to be $6 \mathrm{~mm} \mathrm{~s}^{-1}$ (for Ethmodiscus rex), with diameter of $1 \mathrm{~mm}$. In that case, for $v=10^{-6} \mathrm{~m}^{2} \mathrm{~s}^{-1}$ a value of $R e=6$ is obtained, indicating that in that case, there is a departure from Stokes equation (Lande \& Woods, 1987; Reynolds, 1984), that is inertia forces overwhelm viscous forces. However, this example is an extreme one and calculated values of $R e$ for most of planktonic algae lie within the limit of the laminar flow $(R e<0.1)$, in which case their settling velocity do not depart significantly from the Stokes equation. In some cases, the settling velocity of living cells is different from those of dead cells (Smayda, 1970). The reason for this departure lies in the fact that living cells have found adaptive mechanisms to regulate their settling velocity through changes in their density, composition, secretion of mucilage, regulation of ions over their growth cycle, selecting the most favourable conditions for their habitat (Bienfang, Szyper, \& Laws, 1998; Granata, 1991; Reynolds, 1984). The swimming/ sinking rate of the cells will be affected by turbulent motion only if the cell density is significantly greater than that of the fluid, which would be unusual for most planktonic cells. For very heavy particles, particle inertia causes the particle trajectory to deviate from the streamline of the fluid and particles actually sediment faster as a result of the non-linearities in the drag forces (Lovalenti \& Brady, 1993; Wang \& Maxey, 1993).

The sinking of particles from the mixed layer can be considered as the sum of two mechanisms: the sedimentation of cells, predicted by the Stokes equation, and the movement induced by turbulence. Both mechanisms are considered in the advection-diffusion equation (Ruiz, 1996),

$\frac{\partial C}{\partial t}=w \frac{\partial C}{\partial z}+K_{z} \frac{\partial^{2} C}{\partial z^{2}}$

where $C$ is the particle concentration over time $(t)$ and depth $(z), w$, the swimming/sinking velocity and $K_{z}$, the vertical eddy (turbulent) diffusion coefficient. The boundary conditions are: no particle flux through the surface (i.e. $w C=\partial C / \partial z$ at $z=h$ ) and a dynamic particle flux at the bed (i.e. $\partial C / \partial t=\partial w C / \partial z$ ).

Eq. (1) can be non-dimensionalized using dimensionless parameters for time $(\tau)$, depth $(\eta)$ and diffussivity $(D)$,

$\tau=t w / h, \eta=z / h, D=K_{z} / w h$

where $h$ is the depth of the mixed layer.

In the mixed layer, turbulent mixing can be parameterized as

$K_{z}=0.2 \frac{\varepsilon}{N^{2}}$

where $N$ is the Brunt-Vaisälä frequency and $\varepsilon$, energy dissipation rate. Thus, in a finite microlayer with a constant density (parameterized by the $N$ ), $K_{z}$ is solely determined by the energy dissipation rate, $\varepsilon$.

Many ecosystems are easily described using a simple model that assumes a well-mixed layer with a uniform distribution of particles (Jackson, 1990),

$\frac{\mathrm{d} \bar{C}}{\mathrm{~d} t}=-\frac{w}{h} \bar{C}$

where $C$ is the average concentration of particles in the mixed layer. Previous studies devoted to the settling 
dynamics of particles in a turbulent flow point out the possibility that turbulence can alter their settling velocities (Wang \& Maxey, 1993). Ruiz (1996) and Ruiz et al. (1996) discuss the fact that turbulence motions affect the sedimentation flux $(w C)$ and, therefore, modify the phytoplankton distribution $(\partial C / \partial z)$. In order to correct the sedimentation rate to a more realistic one, they propose a new model (Ruiz, 1996),

$$
\frac{\mathrm{d} C}{\mathrm{~d} t}=-F w \frac{\bar{C}}{h}
$$

where $F$ is the ratio of the concentration at the bottom of the mixed layer to the average vertical concentration. Sinking tends to accumulate particles at the bottom of the mixed layer (corresponding to high values of $F$ and $D<1$ ) although diffusion tends to homogenize the distribution of particles in the mixed layer (corresponding to low values of $F$ and $D>1$ ). Also, $F$ has been found to be strongly dependent on $D$ when $D<1$. On the other hand, $F$ is not sensitive to the $D$ values for $D>1$, which gives $F=1$. In that case, changes in turbulence do not imply big changes in the sedimentation flux. However, for the case of cells, which have $D<1$, turbulence has an important effect in the sedimentation flux through $F$ (Ruiz et al., 1996).
Other factors may affect the value of $F$, such as the growth rate. That is, the vertical distribution of phytoplankton might be more dependent on the physical factors that determine the growth rate of cells than on the turbulence and sinking. Ruiz et al. (1996) suggested that the importance of the growth rate on the vertical distribution can be evaluated by means of two non-dimensional parameters, $P_{1}=r h / w$ and $P_{2}=(\partial r / \partial z) h^{2} / w$, where $r$ is the growth rate. For $P_{1}>1$ and $P_{2}>1$, the growth rate is important in determining the vertical distribution of phytoplankton. For the microorganisms that control their position in the water through motility, the non-dimensional diffusivity is defined as $D=K_{z} / v h$, where $v$ is the swimming velocity instead of sinking velocity used in the last definition of $D$. For values of $D>1$, the cells cannot control their position in the water column, and the turbulence determines their distribution.

\section{Methods}

The study site was situated at the northeast (NE) coast of Spain (Fig. 1a), in the Fenals Point (Fig. 1b). From measurements of the light intensity made monthly during 1 -year period, a minimum value of $4 \%$ of the
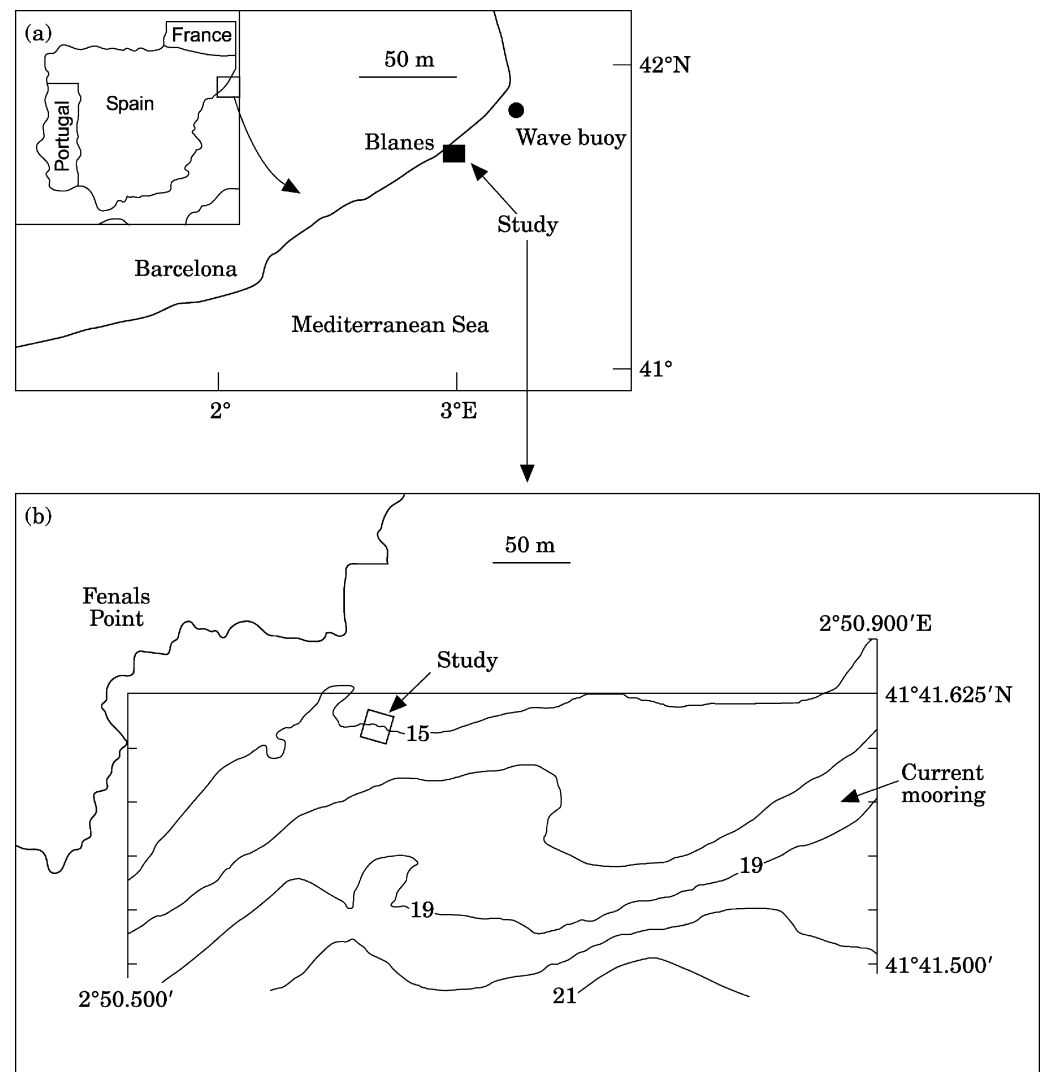

Fig. 1. A map of the study site showing (a) the location of the studied zone (Fenals Point) on the NE coast of Spain and (b) the near shore bathymetry of Fenals Point. 
subsuperficial light intensity was found to reach the bottom of the water column (E. Gacia, personal communication). Therefore, the photic layer coincided with the depth of the water column. Two field campaigns were carried out, the first campaign was carried out on 2 June 1998 and the second campaign was carried out on 5 June 1998. Different weather and flow conditions were encountered on these 2 days.

A meteorological station and a current meter mooring with three Anderaa current meters were located near the sampling station. Current data were collected every $10 \mathrm{~min}$ at 2,5 and $10 \mathrm{~m}$ above the bottom, to characterize the large-scale forcing in the water column. Errors in Anderaa were below $1 \mathrm{~cm} \mathrm{~s}^{-1}$. A wave gage, which was deployed near the current meter mooring, was damaged and returned no data during both surveys. Therefore, time series of wave height were obtained from a Wave Rider buoy located $30 \mathrm{~km} \mathrm{NE}$ of Fenals Point, in $90 \mathrm{~m}$ of water off Palamós, Spain. This surface buoy sampled at a frequency of $2 \mathrm{~Hz}$ with data averaged to 1-h time bins.

A microstructure probe (MST profiler of the Joint Research Center) was deployed every hour, from 1 to 6 June, to profile water density, salinity, temperature, eddy diffusivity and Brunt Väisälä frequency between 2 and $16 \mathrm{~m}$ depth. Subsequently, dissipation rate and potential density were calculated. The MST profiler was equipped with standard CTD sensors and with microstructure and control sensors (Prandke \& Stips, 1998). The standard CTD sensors were the temperature $(\mathrm{Pt}$ 100), the conductivity (7-Pole-cell) and the pressure sensors. The microstructure sensors were the shear sensor
Table 1

Flow conditions at the study site (wind speed, significant wave height $\left(H_{1 / 3}\right)$, mean wave period, principal wave direction $\left(\theta_{w}\right)$, mean current direction $\left(\theta_{c}\right)$ )

\begin{tabular}{lclllc}
\hline Day & $\begin{array}{l}\text { Wind speed } \\
\left(\mathrm{m} \mathrm{s}^{-1}\right)\end{array}$ & $\begin{array}{l}H_{1 / 3} \\
(\mathrm{~m})\end{array}$ & $\begin{array}{l}\text { Wave period } \\
(\mathrm{s})\end{array}$ & $\begin{array}{l}\theta_{w} \\
(\text { degrees })\end{array}$ & $\begin{array}{l}\theta_{c} \\
(\text { degrees })\end{array}$ \\
\hline 2 June & 3 & 0.41 & 3.0 & 2 & 204 \\
5 June & 13 & 0.96 & 4.3 & 331 & 59 \\
\hline
\end{tabular}

Temporal means were calculated over the duration of the low-energy (2 June) and over the high-energy periods (5 June).

(airfoil, PNS93), a fast temperature (microthermistor, FP07) and a special acceleration sensor to check the profiler movements. Sampling was done at $1024 \mathrm{~Hz}$ and spiky data were detected and removed by using a filter that determines the local variance of the signal. Lowfrequency disturbances and high-frequency noise were removed applying a band pass filter to the data.

Profiles of particle size distribution were measured with an in situ particle size analyser (Lisst-100, Sequoia Scientific, Inc.). Lisst-100 consists of a laser beam, an array of 32 detector rings to analyse the light received, a data storage unity and a battery system. Using a procedure based on the laser diffraction theory, Lisst100 measures the particle volume concentration of particles for 64 size classes logarithmically spaced in the range $1.2-200 \mu \mathrm{m}$. By integrating over the whole spectra of size classes, the total particle volume concentration of the suspension of particles can be obtained. The water depth, with a resolution of $5 \mathrm{~cm}$, is also recorded by means of a pressure sensor that is supported with the instrument.

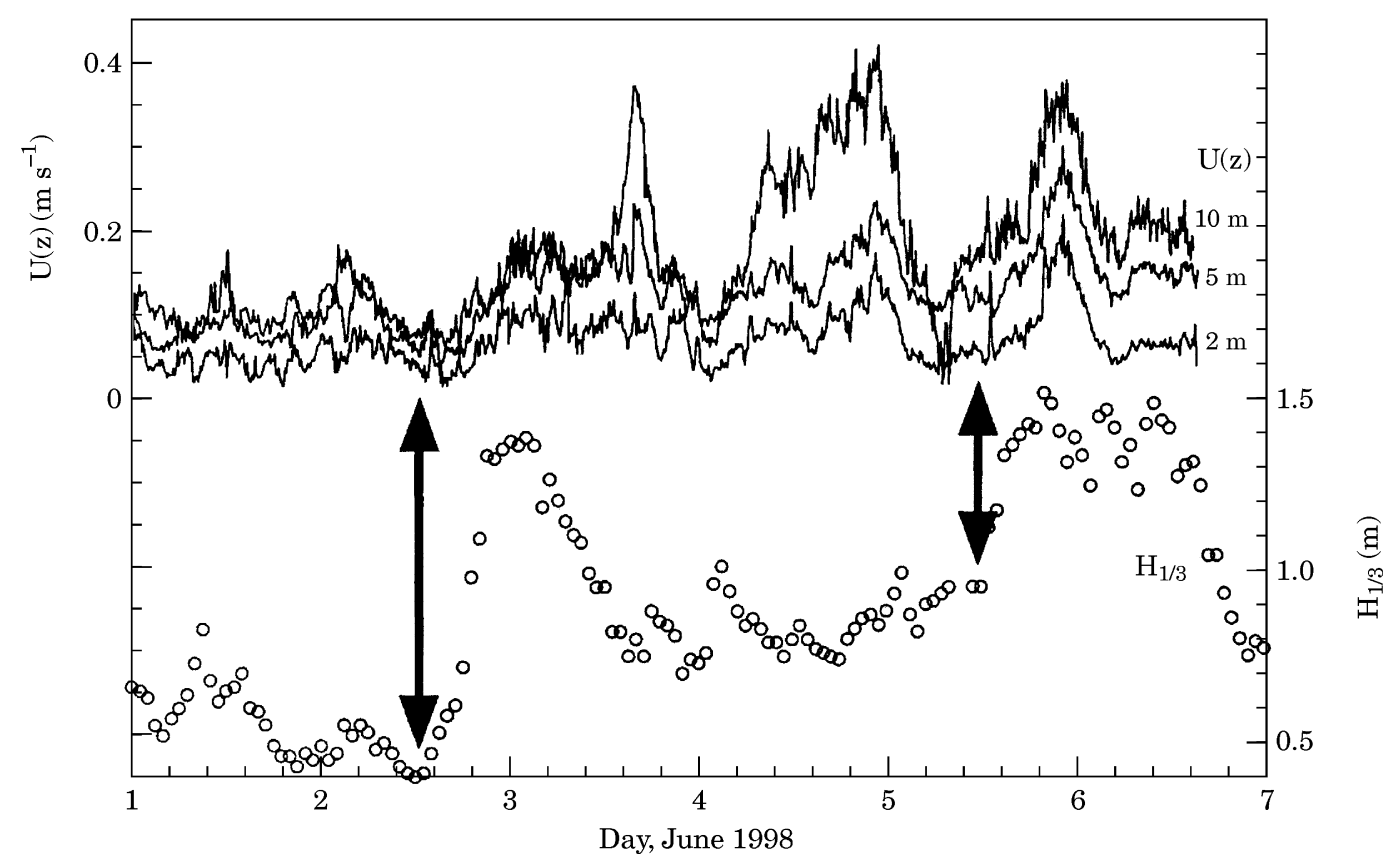

Fig. 2. A time series of significant wave height $(\mathrm{m})$ and mean currents $\left(\mathrm{m} \mathrm{s}^{-1}\right)$ at different depths of the water column from 1 to 6 June, 1998. In this study, depths are considered from the bottom of the water column. 
From 1 to 5 June, water samples were taken over depth to identify the population of phytoplankton present in the water column. Samples were incubated at different PAR conditions in order to evaluate the growth rate of these species collected on different days. Phyto-plankton biomass was analysed by pigment extracted using HPLC. A volume of $2000 \mathrm{ml}$ was filtered onto $\mathrm{GF} / \mathrm{F}$ filters and immediately frozen in liquid nitrogen. Before analysis by HPLC, the filters were thawed and placed in $6 \mathrm{ml} \mathrm{90 \%} \mathrm{acetone,} \mathrm{sonicated} \mathrm{on} \mathrm{ice}$ for $10 \mathrm{~min}$ and extracted for $24 \mathrm{~h}$ at $4{ }^{\circ} \mathrm{C}$. The filter and cell debris were filtered from the extract using disposable syringes and $0.2 \mathrm{~mm}$ teflon syringe filters. Extract $(1 \mathrm{ml})$ and $0.3 \mathrm{ml}$ water were transferred to HPLC vials and placed in the cooling rack of the HPLC. The samples were injected into a Shimadzu LC-10A HPLC system, according to the method described by Wright et al. (1991). The HPLC system was calibrated with pigment standards from The International Agency for ${ }^{14} \mathrm{C}$ Determination, DHI-Water and Environment, Denmark. Peak intensities were routinely confirmed by diode array.

\section{Results}

During the first week of June 1998, wind and current speeds and wave heights increased and current and wave directions shifted during the passage of a storm front

(a) Temperature $\left({ }^{\circ} \mathrm{C}\right)$

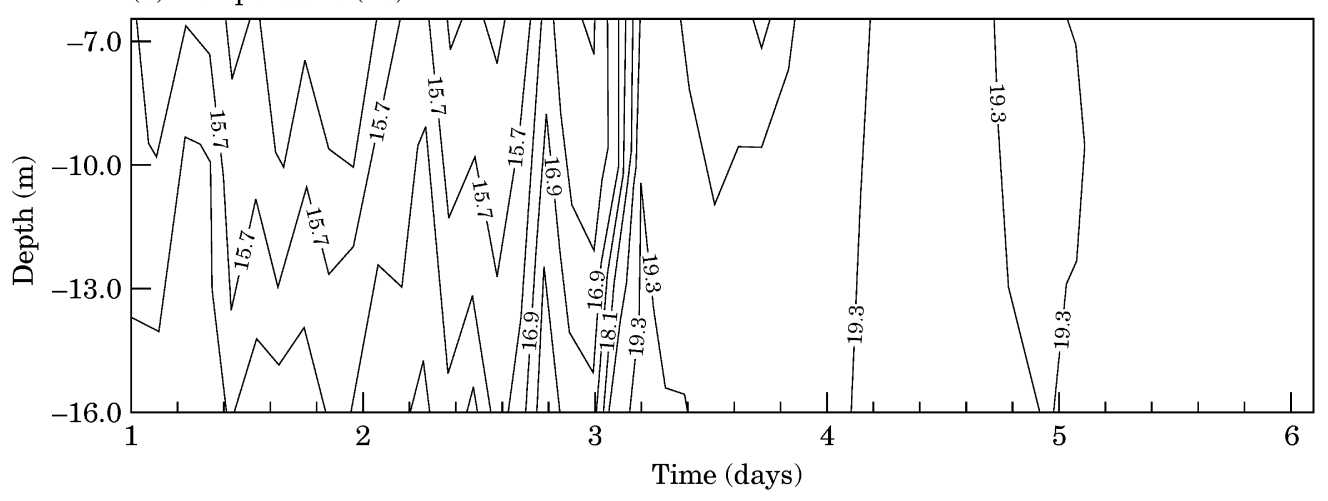

(b) Potential density $\left(\mathrm{Kg} \mathrm{m}^{-3}-1000\right)$

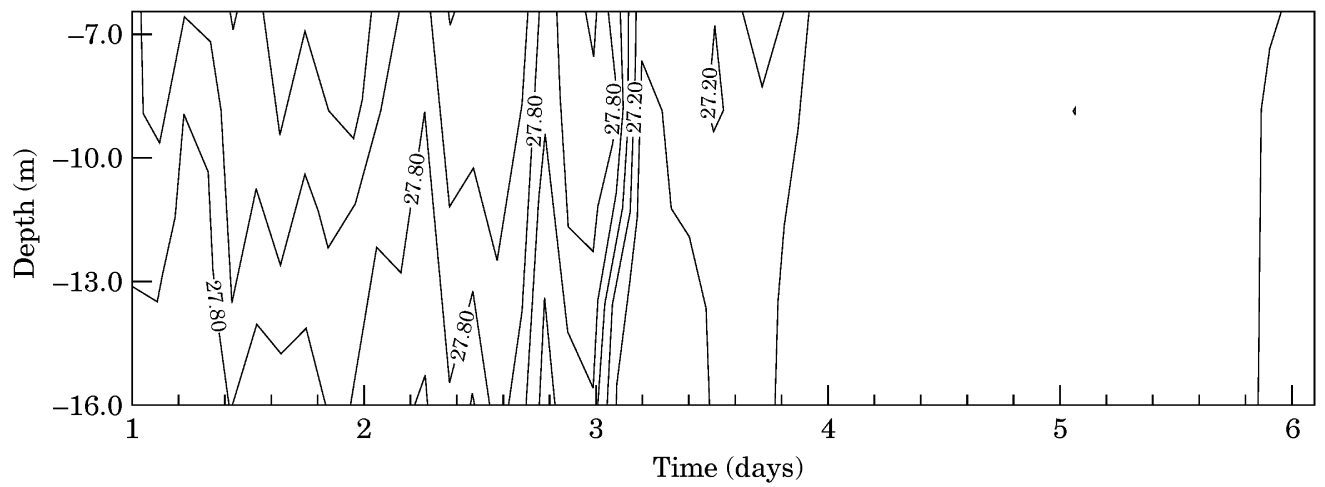

(c) $\mathrm{K}_{\mathrm{z}}\left(\mathrm{m}^{2} \mathrm{~s}^{-1}\right)$

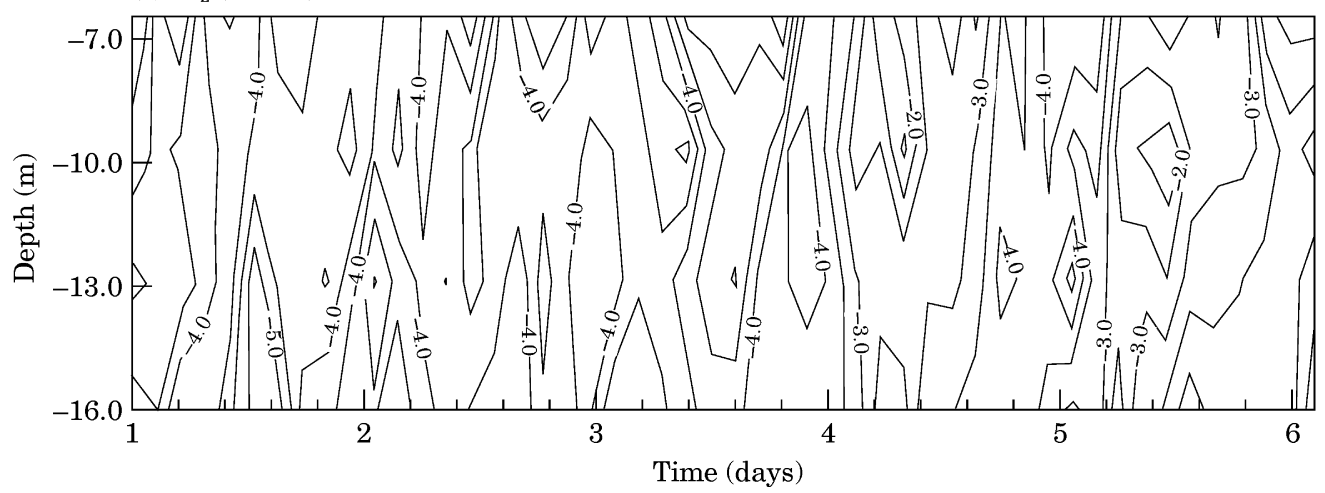

Fig. 3. (a) Temperature, (b) potential density and (c) eddy diffusivity (in log values) maps obtained with the microstructure probe from 1 to 6 June. Profiles were done every hour. 
(Table 1). From the morning of 1 June to the evening of 2 June, current speeds were low $\left(\sim 0.05 \mathrm{~m} \mathrm{~s}^{-1}\right)$ and the maximum wave height was $<0.75 \mathrm{~m}$ (Fig. 2). By 3 June, current speeds and wave height increased to the maximum values of $\sim 0.40 \mathrm{~m} \mathrm{~s}^{-1}$ and $\sim 1.50 \mathrm{~m}$, respectively, which were related to the passage of a storm front.

The water column presented a stratified structure from 1 June until 3 June, as can be seen from both the temperature and potential density maps (Fig. 3a, b, respectively). From 3 June to the end of the campaign (6 June), the water column presented a homogeneous structure. This change of the structure can be attributed to the mixing conditions over the water column, which presented higher values of the eddy diffusivity after 3 June than before, as can be seen from the map of the eddy diffusivity (Fig. 3c).

Profiles of particle concentration were done during the late mornings of 2 and 5 June. During this time, several microstructure profiles were carried out every hour. Eddy diffusivity values obtained from the micro-structure profiles during 2 and 5 June were averaged over the period of time when the particle size measurements were carried out in order to better estimate differences between values of the mixing in both days (Fig. 4). After 2 June, the lower value of the eddy diffusivity of the order of $\sim 10^{-3}\left(\mathrm{~m}^{2} \mathrm{~s}^{-1}\right.$ ) increased (Fig. 4a) to a value of $\sim 10^{-2} \mathrm{~m}^{2} \mathrm{~s}^{-1}$ on 5 June (Fig. 4b).

Particle size distributions over depth showed four main peaks. For this reason, the concentration of particles was integrated in different size ranges corresponding to these different peaks; particles with diameters in the range $1.2-2 \mu \mathrm{m}$, particles in the range $3-10 \mu \mathrm{m}$, particles in the range $10-30 \mu \mathrm{m}$ and particles in the range $30-200 \mu \mathrm{m}$. Particle volume concentration profiles (in $\mu 11^{-1}$ ) for each of these ranges are presented in Fig. 5, for the 2 days studied. Points are the average of 10 measurements of the particle volume concentration made at each depth. In order to see the low variability of the particle volume concentration results, the mean standard deviation (SD) values of the particle volume concentration for the four ranges studied over the whole water column are presented in Table 2 . Particle volume concentration profiles corresponding to the ranges $1.2-2$ and $3-10 \mu \mathrm{m}$ present different structures in the whole water column for 2 and 5 June. For these ranges, the overall value of the particle volume concentration decreases during 2-5 June. Although large particles (ranges $10-30$ and $30-200 \mu \mathrm{m}$ ) show an increase of the particle volume concentration at the surface (Fig. 5), their particle number concentration is relatively low and this increase can not be distinguished in the particle number concentration profiles (Fig. 6). Large particles present an homogeneous vertical distribution with the same values, approximately, for both 2 and 5 June. (a) June 2

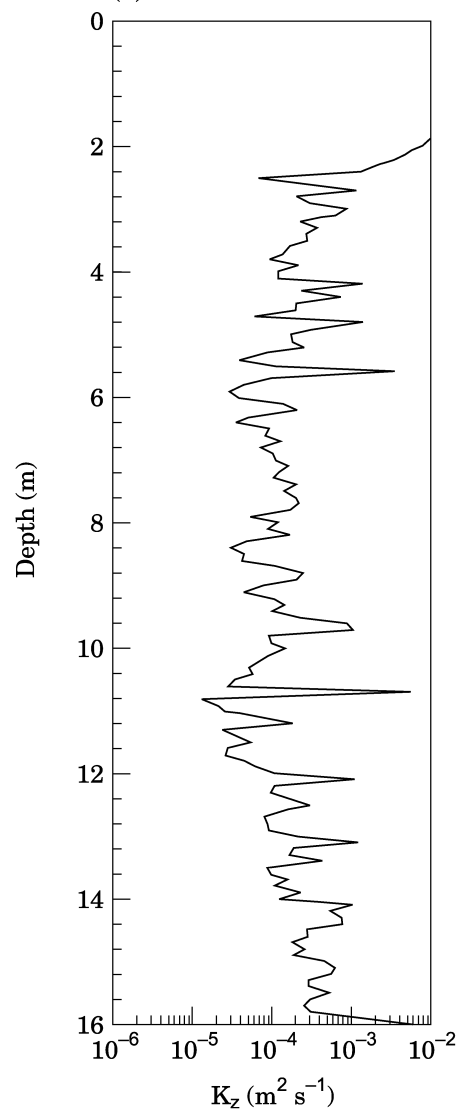

(b) June 5

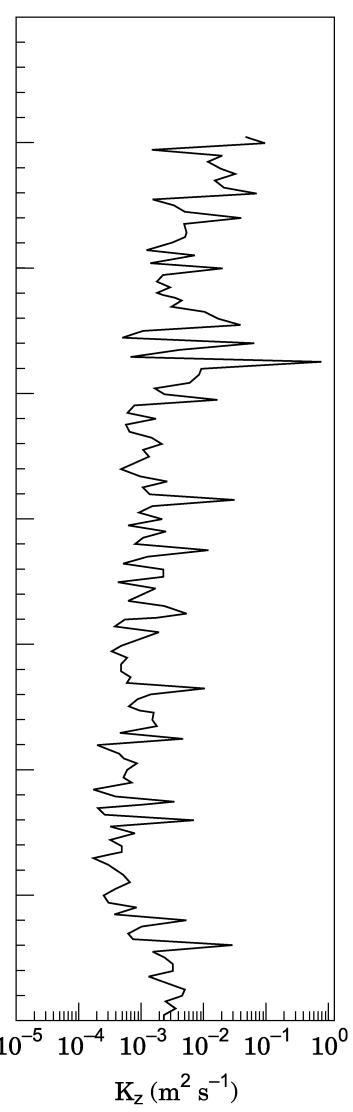

Fig. 4. Mean eddy diffusivity profiles obtained with the microstructure probe on 2 and 5 June. Time averages were done over the period of time when the particle size measurements were carried out.

Prymnesiophytes, Prasinophytes, Pelagophytes, Dinoflafellates, Cryptophytes and Cyanobacteria were all present in the water column, based on data from the microscopic examination of the samples harvested at different depths. The temporal evolution of the biomass of these populations are presented in Fig. 7, with the largest values corresponding to the group Prymnesiophytes, which also presents a maximum on 2 June. Using characteristic dimensions from the literature (Table 3), and also in accordance with the observations of the samples under the microscope, these phytoplankton groups were assigned to the different size ranges of particles from the Lisst-100 (Figs. 5 and 6). Cyanobacteria was assigned to the size range from 1.2 to $2 \mu \mathrm{m}$; Prymnesiophytes, Prasinophytes and Cryptophytes from 3 to $10 \mu \mathrm{m}$; Dinoflagellates from 10 to $30 \mu \mathrm{m}$ and from 30 to $200 \mu \mathrm{m}$; and Pelagophytes from 30 to $200 \mu \mathrm{m}$. Table 3 also summarizes other important characteristics of these phytoplankton groups, including settling/ swimming velocity, flagellated species and growth rate, based on the incubation carried out under different PAR conditions for each day. Estimates of growth for Cyanobacteria at high PAR are probably biased (too 

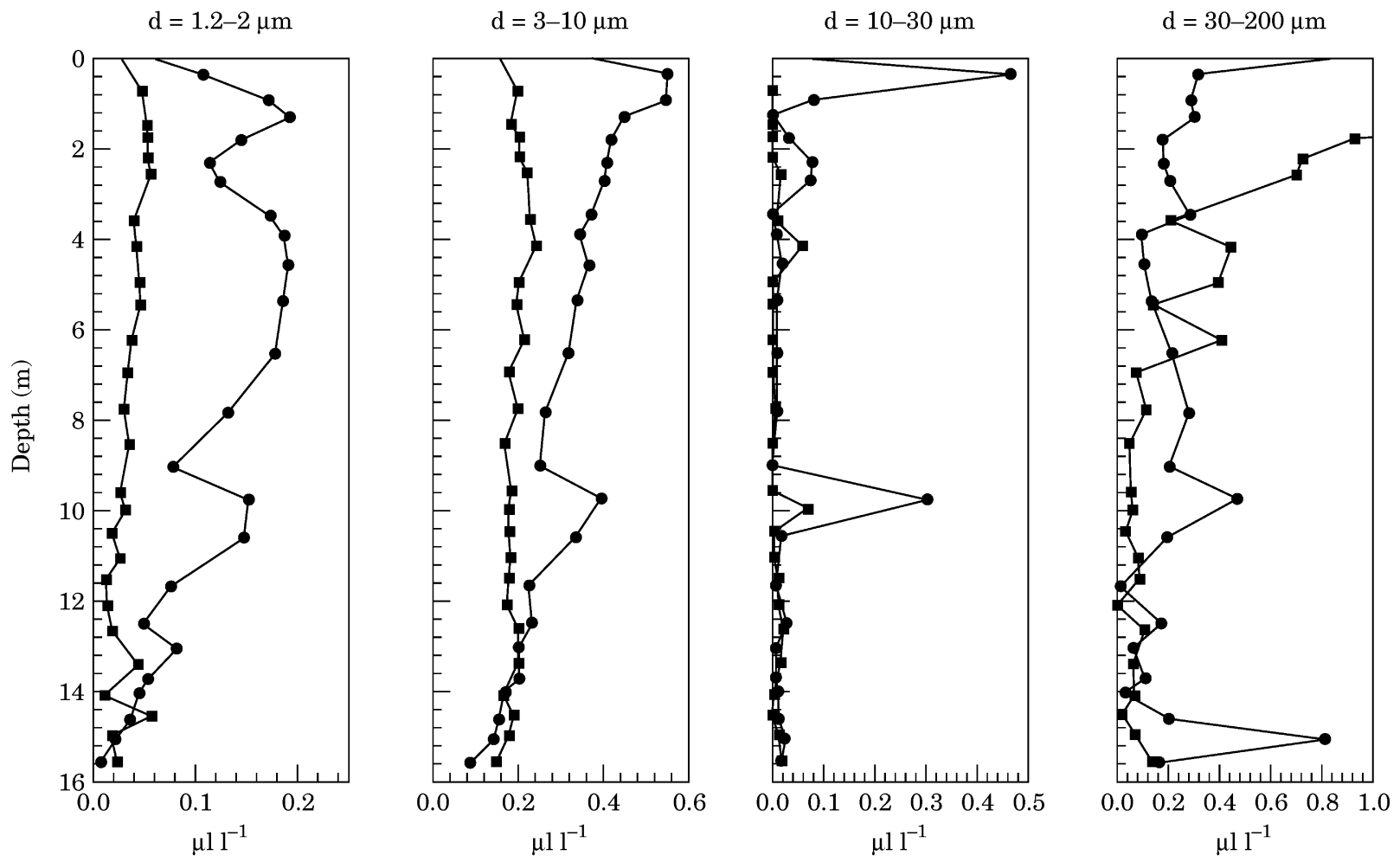

Fig. 5. Particle volume concentration profiles (in $\mu 1^{-1}$ ) obtained with Lisst-100 on $2(\bullet)$ and 5 June (घ) for each of the size ranges analysed: $1.2-2$, $3-10,10-30$ and $30-200 \mu \mathrm{m}$.

high) as biomass were calculated from the diagnostic pigment zeaxanthin, which is used for protection to high light.

\section{Discussion}

Changes in the weather conditions measured from 2 to 5 June affected the structure of the whole water column, increasing turbulent mixing in the water column with values of the eddy diffusivity one order of magnitude higher than before the passage of the storm (Fig. 3c). This change in the structure of the water column was demonstrated as a change in the temperature and in the potential density (Fig. 3a, b, respectively). When mixing excursions dominate over swimming motions, i.e. when $D=K_{z} / h v>l$, then turbulence determines the distribution of phytoplankton cells in

Table 2

Mean SD of the particle volume concentration profiles over the whole water column on both days ( 2 and 5 June) for each of the size ranges analysed

\begin{tabular}{lllll}
\hline & \multicolumn{3}{l}{$\mathrm{SD}\left(\mu \mathrm{l}^{-1}\right)$} & \\
\cline { 2 - 5 } & Range & Range & Range & Range \\
Day & $1-2 \mu \mathrm{m}$ & $3-10 \mu \mathrm{m}$ & $10-30 \mu \mathrm{m}$ & $30-200 \mu \mathrm{m}$ \\
\hline 2 June & 0.02 & 0.05 & 0.08 & 0.09 \\
5 June & 0.01 & 0.1 & 0.06 & 0.08 \\
\hline
\end{tabular}

the water column. For a water column depth of $h=16 \mathrm{~m}$ and a mean turbulent diffusivity of $K_{z} \sim 10^{-3} \mathrm{~m}^{2} \mathrm{~s}^{-1}$ on 2 June, turbulent motion could affect the vertical particle distribution, provided, the swimming velocity of particles was $v<5.4 \mathrm{~m} \mathrm{~d}^{-1}$, which corresponded to a $75 \%$ of the total phytoplankton population (see Table 3 ). On 5 June, the eddy diffusivity was larger $\left(K_{z} \sim 10^{-2}\right.$ $\mathrm{m}^{2} \mathrm{~s}^{-1}$ ) and turbulence was important for particles with $v<54 \mathrm{~m} \mathrm{~d}^{-1}$, which corresponded to a $100 \%$ of the total phytoplankton population (Table 3). Consequently, our observations indicate that nearly the whole phytoplankton population followed turbulent fluctuations under both low- and high-energetic conditions.

The particle size distribution was measured with Lisst-100 and the peaks obtained were assigned to different phytoplankton populations observed with the microscope from 30 fields of samples harvested at different depths of the water column. Despite the fact that no counts were done under the microscope to validate the results of the concentrations measured with Lisst-100, the presence of other populations, such as detritus would contribute to a degradation products of pigments, which were not detected from the analysis of different pigments of the samples harvested from the water column. Beside detritus, particles, such as marine snow (with diameter $>500 \mu \mathrm{m}$ ) cannot be detected with Lisst-100 because of its limited measurable range (see 

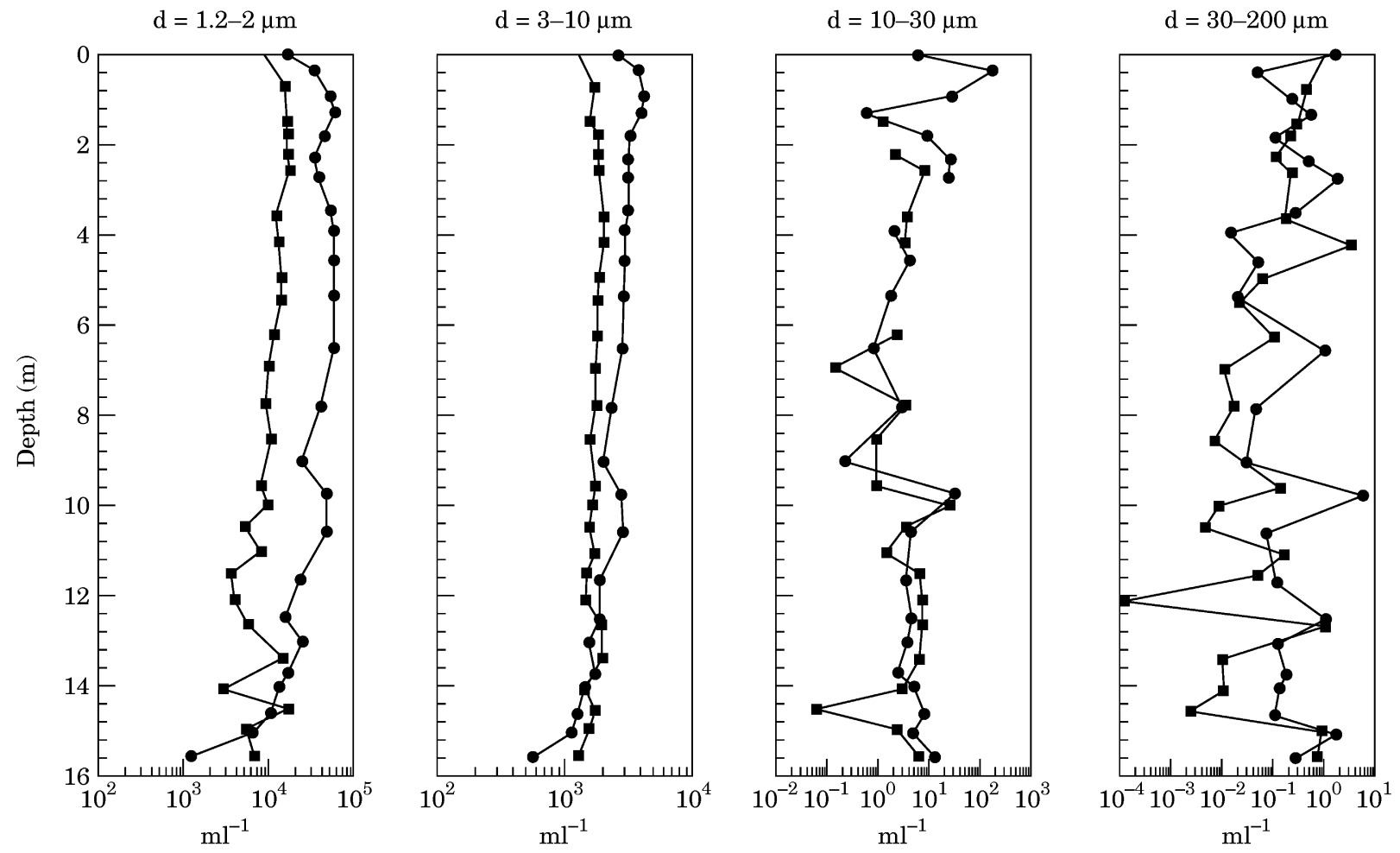

Fig. 6. Number concentration profiles (in $\mathrm{ml}^{-1}$ ) obtained with Lisst-100 on 2 June $(\bullet)$ and 5 June (®) for each of the size ranges analysed: $1.2-2$, $3-10,10-30$ and $30-200 \mu \mathrm{m}$.

Section 3). Therefore, any aliassing of the results of the concentration obtained with Lisst-100 due to the presence of other particles could be neglected.

In order to validate Eq. (5) in this situation, the dependence of $F$ on the growth rate of cells $(r)$ was

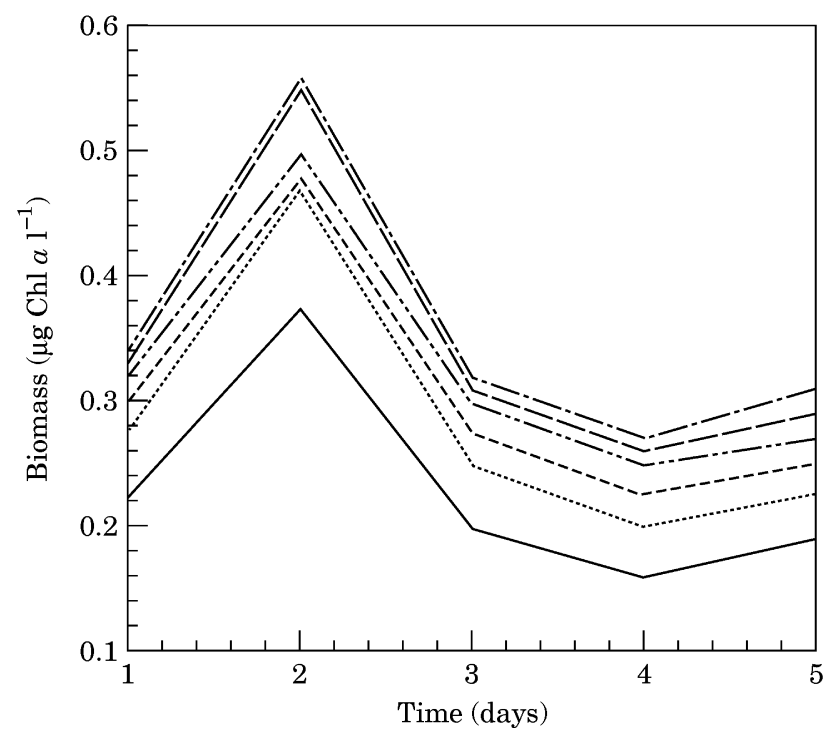

Fig. 7. Temporal variation in phytoplankton biomass groups at Fenals Point, Spain. - Cyanobacteria; ... Cryptophytes; - - - Dinoflagellates; - .. - .. Pelagophytes; - - Prasinophytes; - . - . Prymnesiophytes. evaluated. For this purpose, the non-dimensional parameter $P_{1}=r h / w$ must be $<1$ for turbulence to dominate growth. The values of $r h / w$, calculated from the values of $r$ obtained for each group, are shown in Table 3. All the values were found higher than 1. For this reason, the validity of this equation in this case is questioned. Since turbulent mixing dominates the vertical terms, growth should be dependent on $K_{z}$ and not on sinking or swimming. Therefore, we suggest that a better parameter is the ratio of the time scale of vertical mixing to the time scale of growth, $\Phi=r h^{2} / 2 K_{z}$. For $\Phi>1$, growth dominates over mixing and for $\Phi<1$, mixing dominates over growth. In this study, Table 4 indicates that for all plankton groups, the time scale of growth was large relative to the mixing time only after the storm, giving values of $\Phi<1$. Thus, vertical mixing was controlling the vertical distribution of cells on 5 June, but local production of cells was important before the storm.

If we consider the horizontal plankton distributions based on the time series of plankton (i.e. assume Taylor's hypothesis, $x=u t$, to convert from a temporal to a spatial domain), then it becomes evident that the time scale for growth was dominated by horizontal advection, i.e. $r h \ll u$. Values of the particle concentration for the smallest particles (with diameters in the size ranges 1.2$2 \mu \mathrm{m}$ and $3-10 \mu \mathrm{m}$ ) obtained on 5 June were smaller in the whole column than those obtained on 2 June (Figs. 5 and 
Table 3

Biological information of the major plankton groups found on 2 and 5 June

\begin{tabular}{|c|c|c|c|c|c|c|c|}
\hline Plankton group & $\begin{array}{l}C_{2} \text { Chl } a \\
\left(\mu \mathrm{gl}^{-1}\right)\end{array}$ & $\begin{array}{l}C_{5} \text { Chl } a \\
\left(\mu \mathrm{g}^{-1}\right)\end{array}$ & $D^{\mathrm{a}}(\mu \mathrm{m})$ & Flagella & $\begin{array}{l}w(\text { or } v) \\
\left(\mathrm{m} \mathrm{d}^{-1}\right)\end{array}$ & $r\left(\mathrm{~d}^{-1}\right)$ & $P_{1}=r h / w$ \\
\hline Prymnesiophytes & 0.35 & 0.20 & 10 & Yes & $\pm 0.72-3.6^{\mathrm{b}}$ & $0.4-1.1$ & $1.8-24.5$ \\
\hline Prasinophytes & 0.10 & 0.04 & $<10$ & Yes & $\pm 24-50^{\mathrm{c}}$ & $0.4-1.2$ & $0.13-0.8$ \\
\hline Pelagophytes & 0.02 & 0.03 & 50 & Yes & $\pm 0.72-3.6^{\mathrm{b}}$ & $0.3-0.7$ & $1.3-15.6$ \\
\hline Dinoflagellates & 0.04 & 0.02 & 80 & Yes & $\pm 24-50^{\mathrm{c}}$ & NA & - \\
\hline Cryptophytes & 0.04 & 0.01 & 5 & Yes & $\pm 0.72-3.6^{\mathrm{b}}$ & $0.2-0.7$ & $0.9-15.6$ \\
\hline Cyanobacteria & 0.00 & $<0.01$ & 1 & No & $10^{-2 \mathrm{~d}}$ & $0.6-1.1$ & $960-1760$ \\
\hline
\end{tabular}

Biomass measured on $2\left(C_{2}\right)$ and 5 June $\left(C_{5}\right)$, estimated diameter, flagella, estimated swimming $(w)$ /sinking $(v)$ velocities, measured growth rates

$(r)$ and values of the parameter $P_{1}=r h / w$.

NA, not analysed.

a Delgado and Fortuño (1991).

b Round (1984).

c Eppley, Reid, Cullen, and Stewart (1984).

'Stokes' law where $\rho=1.065 \mathrm{~kg} \mathrm{~m}^{3}$ and a spherical geometry.

6). This change cannot be explained by the vertical mixing because, as was said before, changes in turbulence do not imply big changes in the sedimentation flux when $D>1$ (see Section 2). Moreover, coagulation due to mixing cannot be the reason of this decrease in the number of the smaller particles, because the concentration of the largest particles did not increase. Therefore, this change can be only caused by the advection of mass of water, with lower chlorophyll concentrations, into the study site after the passage of the storm. The presence of a second water mass is sustained by a rise in the temperature of the water column during 2-5 June, which would suggest that the advected water entering the study zone was warmer than the water prevailing before in this region. This fact is also corroborated while comparing the mean horizontal transport at different water depths $U(z) C$ with the mean vertical transport $K_{z} \mathrm{~d} C / \mathrm{d} z$, where $U(z)$ is the mean horizontal velocity of the flow obtained with the Anderaa current meters located at 2, 5 and $10 \mathrm{~m}$ above the bottom, and $C$ is the concentration of particles in the size range from 1.2 to $10 \mu \mathrm{m}$ at the same water depths measured with Lisst-100. Values of $U(z) C$ were calculated and found larger than values of $K_{z} \mathrm{~d} C / \mathrm{d} z$ for all the depths studied (see Table 5), which indicates that horizontal transport processes, i.e. advection processes, were dominant com-

Table 4

Turbulent diffusivities and the maximum value of the ratio between the time scales of mixing and growth $(\Phi)$ on 2 and 5 June for major plankton groups

\begin{tabular}{llllll}
\hline & 2 June & \multicolumn{3}{l}{5 June } \\
\cline { 2 - 3 } \cline { 5 - 5 } $\begin{array}{lllll}K_{z} \\
\text { Plankton group }\end{array}$ & $\begin{array}{l}K_{z} \\
\left(\mathrm{~m}^{2} \mathrm{~s}^{-1}\right)\end{array}$ & $\Phi=r h^{2} / 2 K_{z}$ & $\begin{array}{l}\left.\mathrm{m}^{2} \mathrm{~s}^{-1}\right) \\
\text { Prymnesiophytes }\end{array}$ & 1.6 & $\Phi=r h^{2} / 2 K_{z}$ \\
Prasinophytes & & 1.8 & & 0.16 \\
Pelagophytes & $10^{-3}$ & 1.0 & $10^{-2}$ & 0.18 \\
Dinoflagellates & & NA & & NA \\
Cryptophytes & & 1.0 & & 0.1 \\
Cyanobacteria & & 1.6 & & 0.16 \\
\hline
\end{tabular}

pared to vertical transport processes. For our field observations, both horizontal and vertical transports were important for the plankton distribution so Eq. (1) can be re-cast as (Granata \& Horne, 1985)

$\frac{\partial C}{\partial t}=w \frac{\partial C}{\partial z}+K_{z} \frac{\partial^{2} C}{\partial z^{2}}+u \nabla_{H} C+z C$

where the last two terms specify horizontal advection and local time rate of change (essentially $r C$ for plankton). While vertical mixing processes set growth rates of phytoplankton biomass and sedimentation flux to the bed, advection of cells drove plankton dynamics in this shallow, coastal ecosystem.

\section{Conclusions}

The change in the weather conditions during the stratified period of a coastal ecosystem determined the structure of the water column, increasing the mixing level from a calm period (with $K_{z} \sim 10^{-2} \mathrm{~m}^{2} \mathrm{~s}^{-1}$ ) to a highenergy period (with a mean vertical $K_{z} \sim 10^{-2} \mathrm{~m}^{2} \mathrm{~s}^{-1}$ ). The water column remained stratified during the calmenergy period, whereas in the high-energy period it mixed due to the increase of the turbulence. During both periods, mixing was found to dominate the vertical distribution of phytoplankton, presenting a homogeneous vertical distribution. Therefore, although some physical properties could remain stratified during the calm-energy period, the vertical structure of phytoplank-

Table 5

Mean horizontal $(U(z) C)$ and vertical $\left(K_{z} \mathrm{~d} C / \mathrm{dz}\right)$ components of the transport of particles under the two extreme meteorological conditions studied (low- and high-energetic events)

\begin{tabular}{lll}
\hline & 2 June & 5 June \\
\hline$U(z) C\left(\mathrm{~m} \mathrm{~s}^{-1} \mathrm{mll}^{-1}\right)$ & 0.03 & 0.04 \\
$K_{z} \mathrm{~d} C / \mathrm{d} z\left(\mathrm{~m} \mathrm{~s}^{-1} \mathrm{mll}^{-1}\right)$ & $3 \times 10^{-3}$ & $8 \times 10^{-4}$ \\
\hline
\end{tabular}


ton presented a rather mixed pattern. In the high-energy period, both physical and biological properties appeared well mixed. Growth also played an important role during the calm period and could explain some structures observed in the particle volume concentration profiles for some of the populations.

An overall decrease of the particle volume concentration in the water column was observed from the calmenergy period to the high-energy period. This decrease was caused by the entrance of a warmer water mass, with low particles in suspension, which advected from outside the coast and cleaned the region.

\section{Acknowledgements}

We would like to thank Esperança Gacia for her interesting comments, which helped to improve the article.

\section{References}

Bienfang, P. K., Szyper, J. P., \& Laws, E. (1998). Sinking rates and pigment responses to light-limitation of a marine diatom: implication to dynamics of chlorophyll maximum layers. Oceanology Acta 6, 55-62.

Colomer, J., Serra, T., Piera, J., Roget, E., \& Casamitjana, X. (2001). Observations of a hydrotermal plume in a karstic lake. Limnology and Oceanography 46, 197-203.

Cowles, T. J., \& Desiderio, R. A. (1993). Resolution of biological micro-structure through in situ fluorescence emission spectra. Oceanography 6, 105-111.

Cowles, T. J., Desiderio, R. A., \& Neuer, S. (1993). In situ characterization of phytoplankton from vertical profiles of fluorescence emission spectra. Marine Biology 115, 217-222.

Cowles, T. J., Moum, J. N., Desiderio, R. A., \& Angel, S. M. (1989). In situ monitoring of ocean chlorophyll via laser-induced fluorescence backscattering through an optical fiber. Applied Optics 28, 595-600.

Delgado, M., \& Fortuño, J.-M. (1991). Atlas de fitoplancton del Mar Mediterráneo. Scientia Marina 55, Suppl.1-133.

Eppley, R. W., Reid, F. M. H., Cullen, J. J., \& Stewart, E. (1984). Subsurface patch of a dinoflagellate (Ceratium tripos) off Southern California: patch length, growth rate, associated vertically migrating species. Marine Biology 80, 207-214.

Granata, T. C. (1991). Diel periodicity in growth and sinking rates of the centric diatom Cosconodisus concinnus. Limnology and Oceanography $36,132-139$.

Granata, T. C., \& Home, A. J. (1985). Dispersion characteristics of two planktonic diatoms. Journal of Plankton Research 7, 947-953.
Ignatiaded, L. (1979). The influence of water stability on the vertical structure of a plankton community. Marine Biology 52, 97-104.

Jackson, G. A. (1990). A model of the formation of marine algal flocs by physical coagulation processes. Deep-Sea Research 37, 11971211.

Kiørboe, T., Tiselius, P., Mitchell-Innes, B., Hansen, J. L. S., Visser, A. W., \& Mari, X. (1998). Intensive aggregate formation with low vertical flux during an upwelling-induced diatom bloom. Limnology and Oceanography 43, 104-116.

Lande, R., \& Woods, A. M. (1987). Suspension time of particles in the upper ocean. Deep-Sea Research 34, 61-72.

Li, X., \& Logan, B. E. (1997). Collision frequencies of fractal aggregates with small particles by differential sedimentation. Environmental Science and Technology 31, 1229-1236.

Lovalenti, P. M., \& Brady, J. F. (1993). The hydrodynamic force on a rigid particle undergoing arbitrary time-dependent motion at small Reynolds number. Journal of Fluid Mechanics 256, 561-605.

Prandke, H., \& Stips, A. (1998). Test measurements with an operational microstructure-turbulence profiler: detection limits of dissipation rates. Aquatic Sciences 60, 191-209.

Reynolds, C. S. (1984). The ecology of freshwater phytoplankton (pp. 382). Cambridge: Cambridge University Press.

Round, F. E. (1984). The ecology of algae (pp. 653). Cambridge: Cambridge University Press.

Ruiz, J. (1996). The role of turbulence in the sedimentation loss of pelagic aggregates from the mixed layer. Journal of Marine Research $54,385-406$

Ruiz, J., García, C. M., \& Rodríguez, J. (1996). Sedimentation loss of phytoplankton cells from the mixed layer: effects of turbulence levels. Journal of Plankton Research 18, 1727-1734.

Ryther, J. H., \& Hulburt, E. M. (1960). On winter mixing and the vertical distribution of phytoplankton. Limnology and Oceanography 5, 337-338.

Serra, T., \& Logan, B. E. (1999). Collision frequencies of fractal bacterial aggregates with small particles in a sheared fluid. Environmental Science and Technology 33, 2247-2251.

Serra, T., Colomer, J., \& Casamitjana, X. (1997). Aggregation and breakup of particles in a shear flow. Journal of Colloid and Interface Science 187, 466-473.

Smayda, T. J. (1970). The suspension and sinking of phytoplankton in the sea. Oceanography Marine Biology Annual Review 8, 353-414.

Tremblay, J. E., Legendre, L., \& Therriault, J. C. (1997). Sizedifferential effects of vertical stability on the biomass and production of phytoplankton in a large estuarine system. Estuarine, Coastal and Shelf Science 45, 415-431. doi:10.1006/ECSS.1996.0223.

Wang, L. P., \& Maxey, M. R. (1993). Settling velocity and concentration distribution of heavy particles in homogeneous isotropic turbulence. Journal of Fluid Mechanics 256, 27-68.

Wright, S. W., Jeffrey, S. W., Mantoura, R. F. C., Llewellyn, C. A., Bjørnland, T., Repeta, D., \& Welschmeyer, N. (1991). Improved HPLC method for the analysis of chlorophylls and carotenoids from marine phytoplankton. Marine Ecology Progress Series 77, 183-196. 